\title{
Penerapan Metode WASPAS Dalam Penempatan Hawker Branded Dunhill Filter
}

\author{
Tiambun Romauli Silalahi*, Abdul Sani Sembiring, Sumiaty Adelina Hutabarat \\ Program Studi Teknik Informatika, Universitas Budi Darma, Medan, Indonesia \\ Email: ${ }^{1}$ Romauli.silalahi234@gmail.com
}

\begin{abstract}
Abstrak-Penempatan lokasi merupakan penjelasan yang dikaitkan dengan tata ruang dari suatu kegiatan ekonomi, dan hal ini selalu dikaitkan pula dengan alokasi geografis dari sumber daya yang terbatas yang pada gilirannya akan berpengaruh dan berdampak terhadap lokasi baik ekonomi atau sosial. Penempatan lokasi merupakan suatu kegiatan strategis yang bertujuan untuk memaksimalkan keuntungan bagi perusahaan. Penempatan lokasi sangat mempengaruhi biaya dan menentukan penghasilan, lokasi sepenuhnya memiliki kekuatan untuk membuat atau menghancurkan strategi bisnis sebuah perusahaan. Untuk menentukan rekomendasi penenmpatan hawker brended dunhill filter di PT. Bentoel Group Asmo Medan dapat digunakan metode weight aggregated sum product assessment (WASPAS). Metode Waspas dapat digunakan untuk perangkingan penempatan lokasi Hawkwer Dunhill Filter dengan kriteria yang telah ditentukan.
\end{abstract}

Kata Kunci: Penempatan; Hawker Brended Dunhill Filter; Sistem Pendukung Keputusan; WASPAS.

Abstract-The location placement is an explanation related to the spatial layout of an economic activity, and this is always linked to the geographical allocation of limited resources which in turn will have an effect on and have an impact on both economic and social locations. Placement of location is a strategic activity that aims to maximize profits for the company. Placement of location greatly influences costs and determines income, location completely has the power to make or break a company's business strategy. To determine the recommendation for the placement of hawker brended dunhill filters at PT. Bentoel Group Asmo Medan can use the weight aggregated sum product assessment (WASPAS) method. The Waspas method can be used to rank the Hawkwer Dunhill Filter location with predetermined criteria.

Keywords: Hawker Brended Dunhill Filter; Placement; Decision Support System; WASPAS

\section{PENDAHULUAN}

Penempatan lokasi merupakan penjelasan yang dikaitkan dengan tata ruang dari suatu kegiatan ekonomi, dan hal ini selalu dikaitkan pula dengan alokasi geografis dari sumber daya yang terbatas yang pada gilirannya akan berpengaruh dan berdampak terhadap lokasi baik ekonomi atau sosial. Penempatan lokasi merupakan suatu kegiatan strategis yang bertujuan untuk memaksimalkan keuntungan bagi perusahaan. Penempatan lokasi sangat mempengaruhi biaya dan menentukan penghasilan, lokasi sepenuhnya memiliki kekuatan untuk membuat atau menghancurkan strategi bisnis sebuah perusahaan.

Sistem pendukung keputusan merupakan salah satu dari sistem informasi berbasis komputer atau yang disebut CIBS (Computer Base Information System) yang merupakan sistem interaktif berbasis komputer yang memudahkan pemecahan masalah yang digunakan untuk meningkatkan produktifitas dan kualitas dari orang yang menentukan atau membuat keputusan. Pada dasarnya SPK merupakan pengembangan lebih lanjut dari sistem informasi manajemen terkomputerisasi, yang dirancang sedemikian rupa sehingga bersifat interaktif dengan pemakainnya sifat interaktif ini akan memudahkan integrasi antara berbagai komponen dalam proses pengambilan keputusan seperti prosedur, analisis pengalaman dan wawasan manajerial guna membentuk kerangka keputusan yang bersifat fleksibel[1].

PT. Bentoel Group Asmo Medan adalah bergerak dibidang distribusi rokok. Produk yang didistribusikan yaitu sigaret kretek mesin light mild terdiri Dari Star Mild, Neo Mild, Uno Mild, One Mild, Club Mild, X Mild, Dunhill Mild, Lucky Strike Mild. Dan juga jenis produksi dari sigaret putih mesin terdiri dari Dunhill, Country, Ardath, Lucky Strike PT. Bentoel group menyadari peran dan tanggung jawabnya sebagai distribusi rokok pada komunitas dimana beroperasi, tanggung jawab sosial perusahaan (corporate social responsibility- CSR) merupakan salah satu upaya dalam berkontribusi kepada masyarakat. Untuk menjaga kualitasnya PT. Bentoel Group Asmo Medan harus menjaga persaingan yang baik dengan memasang Rombong Hawker Brended Dunhill Filter di tempat lokasi yang tepat. Hawker Brended Dunhill Filter ini adalah tempat untuk berjualan dan pengiklanan. Melihat pentinganya fungsi Hawker Brended Dunhill Filter ini PT. Bentoel Group Asmo Medan sering kewalahan untuk menentukan penempatan lokasi yang strategis untuk penempatannya.

Masalah penempatan lokasi sering menjadi permasalahan bagi pihak PT.Bentoel Group Asmo Medan karena para pedagang kaki lima (PKL) sering memindahkan hawker dari lokasi yang ditentukan PT ke lokasi yang tidak sesuai dengan syarat penempatan, Maka sering terjadi konflik antara dinas perhubungan dengan Pt.Bentoel, seperti penarikan hawker. ini menjadi permasalahan yang tentu harus diselesaikan oleh Pt. Bentoel Group Asmo Medan supaya tidak terjadi permasalahan dan kerugian. karena setiap satu unit rombong Hawker brended Dunhill filter diinvestasikan kurang lebih Rp. 45.000.000., dengan harga tersebut Perusahaan sangat mengharapkan adannya timbal balik (keuntungan) bagi perusahaan, dan periklanan tercapai. Tetapi karena adannya permasalahan dalam penempatan lokasi tersebut perusahaan sering mengalami kerugian.

Dalam menentukan penempatan Hawker brended dunhil filter ini terlebih dahulu pihak PT. Bentoel atau team leader (TL) melakukan penyeleksian kandidat yang mendaftar sebagai penerima Hawker brended dunhil filter. Setelah 
terpilihnya kandidat yang memenuhi syarat penempatan Rombong ini, maka pihak dari PT. Bentoel Group Asmo Medan akan menempatkan Hawker tersebut ke lokasi si penerima hawker.

Berdasarkan permasalahan di atas, maka diperlukan suatu sistem pendukung keputusan untuk membantu PT. Bentoel Group Asmo Medan untuk menentukan penempatan lokasi yang strategis dengan menerapkan beberapa metode. Sesuai dengan perkembangan teknologi informasi, semakin bertambah pula kemampuan komputer dalam membantu menyelesaikan permasalahan-permasalahan diberbagai bidang diantaranya sistem pendukung keputusan. Dalam sistem pendukung keputusan ada beberapa metode di antaranya Analisycal Hierarcy Process (AHP), Multi-Objective Optimazation On The Basis Of Ratio Analysis(MOORA), Weighted Product (WP), Preference Selection Index (PSI), Simple Additive Weighting (SAW), dan lain-lain[2]-[4].

Penelitian tentang sistem pendukung keputusan juga dilakukan oleh Safrizal Barus dengan menerapkan Weighted Aggregated Sum Product Assesment (WASPAS) yaitu dalam penelitian Pengangkatan guru tetap yang dilakukan pada april 2018. Hasil penelitian membantu bagaimana cara mudah bagi pembuat keputusan untuk menetapkan nilai pada setiap kriteria yang paling relatif baik dari setiap kriteria[5].

\section{METODOLOGI PENELITIAN}

\subsection{Sistem Pendukung Keputusan}

Konsep sistem pendukung keputusan pertama kali diperkenalkan pada tahun 1970-an oleh Michael S.Scott morton dengan istilah management decision model. Sistem pendukung keputusan (SPK) atau Decision Support Systems(DSS) adalah sistem informasi interaktif yang menyediakan informasi, pemodelan, dan pemanipulasian data yang digunakan untuk membantu pengambilan keputusan pada situasi semitersturuktur dan situasi yang tidak terstruktur dimana tak seorang pun tahu secara pasti bagaimana keputusan seharusnya dibuat[1], [6], [7].

\subsection{Hawker Brended Dunhill Filter}

Hawker Brended Dunhill Filter merupakan kios kecil yang disediakan perusahaan PT. Bentoel Group bagi PKL (Pedagang Kaki Lima) untuk membantu usaha UKM (Usaha Kecil Menengah) hal ini dapat membantu para PKL untuk memperoleh penghasilan yang lebih baik. Hawker Brended Dunhill Filter ini adalah tempat berjualan terutama produk rokok dari PT. Bentoel Group, atau juga sering disebut dengan rombong (gerobak jualan) dan adannya papan reklame atau pengiklanan yang juga bisa dimanfaatkan untuk marketing (pemasaran) sebuah brand (merek) atau produk, sehingga terlaksanannya pendapatan yang menguntungkan baik bagi PKL maupun perusahaan. Berdasarkan defenisi diatas dapat diambil satu kesimpulan bahwa Hawker Brended Dunhill Filter adalah salah satu rombong tempat jualan yang disediakan PT. Bentoel untuk para pedagaang kaki lima (PKL).

\subsection{Metode Weighted Aggregated Sum Product Assessment (WASPAS)}

Metode WASPAS adalah sebuah kerangka untuk mengambil keputusan dengan efektif atas persoalan yang kompleks dengan menyederhanakan dan memepercepat proses pengambil keputusan dengan memecahkan permasalahan tersebut kedalam bagian-bagiannya, menata bagian atau variabel ini dalam suatu susunan hirarki, memberi nilai numerik pada pertimbangan subjektif tentang pentingnya tiap variabel dan mensintesis berbagai pertimbangan ini menetapkan varibel dan mensintetis mana yang memiliki prioritas paling tinggi dan bertindak untuk mempenguhi hasil pada situasi tersebut. Metode Waspas ini membantu memecahkan persoalan yang kompleks dengan menstruktur [8], [9].

Mencari prioritas pilihan lokasi yang paling sesuai dengan menggunakan pembobotan. Penerapan metode Waspas, yang merupakan kombinasi unik dua sumber dikenal sebagai MCDM Mapproaches, WMM dan model produk berat (WPM) pada awallnnya memerlukan normalisasi linier dari elemen hasil. Dengan metode WASPAS, kriteria kombinasi optimum. Kriteria pertama yang optimal, kriteria keberhasilan rata-rata tertimbang sama dengan metode WSM. Ini adalah pendekatan yang populer dan diadopsi untuk MCDM untuk mengevaluasi beberapa alternatif dalam beberapa kriteria keputusan.

Adapun langkah-langkah metode WASPAS sebagai berikut:

1. Menentukan Normalisasi Matrix dalam pengambilan keputusan

$$
\mathrm{X}=\left[\begin{array}{cccc}
x 11 & x 12 & \ldots & x 1 n \\
x 21 & x 22 & \cdots & x 2 n \\
\cdots & \cdots & \cdots & \cdots \\
x m 1 & x m 2 & \cdots & x m 3
\end{array}\right]
$$

Jika nilai maksimal dan minimal telah ditentukan maka persamaan sebagai berikut:

Untuk kriteria benefit :

$$
\mathrm{Xij}=\frac{x i j}{\operatorname{maxi} X i j}
$$

Untuk kriteria biaya :

$$
\mathrm{Xij}=\frac{\operatorname{Mini} X i j}{X i j}
$$

2. Menghitung nilai normalisasi matrix dan bobot WASAS dalam pengambilan keputusan

$$
\mathrm{Q}=0,5(x+a)^{n}=\sum_{j=1}^{n} x \mathrm{xijwj}+0,5 \prod_{\mathrm{j}=1}\left(\mathrm{x}_{\mathrm{i}} \mathrm{ij}\right) \mathrm{wj}
$$




\section{HASIL DAN PEMBAHASAN}

Sistem penempatan Hawker Brended Dunhill Filter dilakukan oleh team leader dari Pt. Bentoel Group Asmo Medan. Dalam penempatan lokasi Hawker Brended Dunhill Filter ini berdasarkan kandidat yang terpilih yang memenuhi syarat penempatan, penyeleksian penempatan lokasi Hawker brended dunhill filter ini dilakukan langsung ke lapangan si kandidat yang telah terdaftar sebagai pemohon.

Setelah terpilihnya kandidat penerima hawker yang sesuai dengan kriteria , maka team leader dari PT. Bentoel Group Asmo Medan akan menempatkan Hawker Brended Dunhill Filter tersebut ke lokasi si kandidat yang terpilih. Berdasarkan penelitian yang penulis lakukan, sistem yang sedang berjalan pada PT.Bentoel Group Asmo Medan, didalam penempatan Hawker Brended Dunhill Filter ini sering mempunyai kendala, yaitu penerima hawker sering memindahkan hawker dari tempat yang telah di tentukan perusahaan ke tempat yang tidak sesuai dengan kriteria. maka sering terjadi konflik antara dinas perhubungan dengan pihak perusahaan karena hal yang dilakukan penerima hawker itu melanggar peraturan perundang-undangan. contoh salah satu konflik nya adalah penarikan Hawker brended dunhill filter oleh dinas perhubungan. dengan demikian pihak perusahaan akan mengalami kerugian besar.

Untuk itu cara penyelesaian masalah tersebut dapat menggunakan metode-metode pendukung keputusan dalam menentukan penempatan Hawker brended dunhill filter dengan menggunakan metode Weighted Aggregated Sum Product Assesment (WASPAS). sistem pendukung keputusan Hawker brended dunhill filter ini merupakan suatu aplikasi yang di rancang yang dapat membantu PT. Bentoel Group Asmo Medan dalam mengambil keputusan dengan kriteria-kriteria yang mendukung sesuai sistem.

\subsection{Penerapan Metode WASPAS}

Metode WASPAS merupakan salah satu metode yang dapat mengurangi kesalahan-kesalahan atau mengoptimalkan dalam penaksiran untuk penilaian tertinggi dan terendah. Demikian tujuan utama pendekatan MCDM adalah memilih opsi terbaik dari sekumpulan alternatif dihadapan berbagai kriteria yang salaing bertentangan. Dalam sistem pendukung keputusan penempatan hawker brended dunhil filter di PT.Bentoel Group Asmo Medan dengan menggunakan metode Weighted Aggregated Product Assessment (WASPAS), metode ini dipilih karena sifatya menentukan nilai bobot untuk setiap atribut

Kasus:

1. Fokus Penempatan hawker brended dunhil filter

2. Alternatif Diambil dari daftar nama pemohon yang ingin mendapatkan hawker brended dunhil filter yaitu: Budi sianipar, Dewi Farah, Suminta, Iwan, Johanes , Khadizah, Resita, Lia, Widodo, Dicky

3. Kriterianya adalah Tingkat keamanan(appearance), kondisi lingkungan, lokasi penemptan, kepadatan penduduk, Banyaknya usaha yang mendukung lokasi, persaingan (Kompetitor)

Tabel 1. Rating Kecocokan Setiap Alternatif Pada Setiap Kriteria

\begin{tabular}{ccccccc}
\hline \multirow{2}{*}{ Alternatif } & \multicolumn{7}{c}{ Kriteria } \\
\cline { 2 - 7 } & C1 & C2 & C3 & C4 & C5 & C6 \\
\hline Budi Sianipar & 60 & 96 & 70 & 90 & 90 & 85 \\
Dewi Farah & 100 & 87 & 80 & 80 & 90 & 90 \\
Suminta & 60 & 71 & 62 & 83 & 80 & 85 \\
Iwan & 60 & 61 & 73 & 61 & 70 & 85 \\
Johanes & 60 & 62 & 80 & 73 & 80 & 85 \\
Khadijah & 100 & 62 & 80 & 61 & 73 & 70 \\
Resita & 60 & 90 & 70 & 61 & 60 & 73 \\
Lia & 61 & 85 & 94 & 73 & 65 & 100 \\
Widodo & 73 & 70 & 90 & 80 & 60 & 87 \\
Dicki & 70 & 50 & 87 & 90 & 60 & 80 \\
W & 10 & 5 & 30 & 10 & 30 & 15
\end{tabular}

Data penilaian kriteria yang digunakan didapat dari hasil riset yang diberikan oleh PT.Bentoel, penyeleksian dengan menggunakan metode Weighted Aggregated Product Assessment (WASPAS) langkah selanjutnya yang dilakukan adalah membuat matriks keputusan

$\left[\begin{array}{cccccc}50 & 96 & 70 & 90 & 90 & 85 \\ 100 & 87 & 80 & 80 & 90 & 90 \\ 50 & 71 & 62 & 83 & 80 & 85 \\ 50 & 61 & 73 & 61 & 70 & 85 \\ 50 & 62 & 80 & 73 & 80 & 85 \\ 100 & 62 & 80 & 61 & 73 & 70 \\ 60 & 90 & 70 & 61 & 50 & 73 \\ 61 & 85 & 94 & 73 & 65 & 100 \\ 73 & 70 & 90 & 80 & 50 & 87 \\ 70 & 50 & 87 & 90 & 50 & 80\end{array}\right]$


Journal of Information System Research (JOSH)

Volume 2, No. 4, Juli 2021

ISSN 2686-228X (media online)

Hal: $260-267$

Berdasarkan persamaan ke 2, melakukan normalisasi matriks X

$$
\begin{aligned}
& x 11=\frac{60}{100}=0,6 \\
& x 21=\frac{100}{100}=1 \\
& x 31=\frac{60}{100}=0,6 \\
& x 41=\frac{60}{100}=0,6 \\
& x 51=\frac{60}{100}=0,6 \\
& x 61=\frac{100}{100}=1 \\
& x 71=\frac{60}{100}=0,6 \\
& x 81=\frac{61}{100}=0,61 \\
& x 91=\frac{73}{100}=0,73 \\
& x 101=\frac{70}{100}=0,7 \\
& x 12=\frac{96}{96}=1 \\
& x 22=\frac{87}{96}=0,9062 \\
& x 32=\frac{71}{96}=0,7395 \\
& x 42=\frac{61}{96}=0,6354 \\
& x 52=\frac{62}{96}=0,6458 \\
& x 62=\frac{62}{96}=0,6458 \\
& x 72=\frac{62}{96}=0,6458 \\
& x 82=\frac{90}{96}=0,9375 \\
& x 92=\frac{85}{96}=0,8854 \\
& x 102=\frac{50}{96}=0,5208 \\
& x 13=\frac{70}{94}=0,7446 \\
& x 23=\frac{80}{94}=0,8510 \\
& x 33=\frac{62}{94}=0,6595 \\
& x 43=\frac{73}{94}=0,7765 \\
& x 53=\frac{80}{94}=0,8510 \\
& x 63=\frac{80}{94}=0,8510 \\
& x 73=\frac{70}{94}=0,7446 \\
& x 83=\frac{94}{94}=1 \\
& x 93=\frac{90}{94}=0,9574
\end{aligned}
$$


$x 103=\frac{87}{94}=0,9255$

$x 14=\frac{90}{90}=1$

$x 24=\frac{80}{90}=0,8888$

$x 34=\frac{83}{90}=0,9222$

$x 44=\frac{61}{90}=0,6777$

$x 54=\frac{73}{90}=0,8111$

$x 64=\frac{61}{90}=0,6777$

$x 74=\frac{61}{90}=0,6777$

$x 84=\frac{73}{90}=0,8111$

$x 94=\frac{80}{90}=0,8888$

$x 104=\frac{90}{90}=1$

$x 15=\frac{90}{90}=1$

$x 25=\frac{90}{90}=1$

$x 35=\frac{80}{90}=0,8888$

$x 45=\frac{70}{90}=0,7777$

$x 55=\frac{80}{90}=0,8888$

$x 65=\frac{73}{90}=0,8111$

$x 75=\frac{50}{90}=0,5555$

$x 85=\frac{65}{90}=0,7222$

$x 95=\frac{50}{90}=0,5555$

$x 15=\frac{50}{90}=0,5555$

$x 16=\frac{85}{100}=0,85$

$x 26=\frac{90}{100}=0,9$

$x 36=\frac{85}{100}=0,85$

$x 46=\frac{85}{100}=0,85$

$x 56=\frac{85}{100}=0,85$

$x 66=\frac{70}{100}=0,7$

$x 76=\frac{73}{100}=0,73$

$x 86=\frac{100}{100}=1$ 


\section{Journal of Information System Research (JOSH)}

Volume 2, No. 4, Juli 2021

ISSN 2686-228X (media online)

Hal: $260-267$

$x 96=\frac{87}{100}=0,87$

$x 106=\frac{80}{100}=0,8$

Hasil dari Normalisasi matriks $\mathrm{X}$ diperoleh matriks $\mathrm{X}_{\mathrm{ij}}$

$$
\left[\begin{array}{cccccc}
0,6 & 1 & 0,7446 & 1 & 1 & 0,85 \\
1 & 0,9062 & 0,8510 & 0,8888 & 1 & 0,9 \\
0,6 & 0,7395 & 0,6595 & 0,9222 & 0,8888 & 0,85 \\
0,6 & 0,6354 & 0,7765 & 0,6777 & 0,7777 & 0,85 \\
0,6 & 0,6438 & 0,8510 & 0,8111 & 0,8888 & 0,85 \\
1 & 0,6438 & 0,8510 & 0,6777 & 0,8111 & 0,7 \\
0,6 & 0,6458 & 0,7446 & 0,6777 & 0,6666 & 0,73 \\
0,61 & 0,9375 & 1 & 0,8111 & 0,7222 & 1 \\
0,73 & 0,8854 & 0,9574 & 0,8888 & 0,6666 & 0,87 \\
0,7 & 0,5208 & 0,9255 & 1 & 0,6666 & 0,8
\end{array}\right]
$$

3.langkah selanjutnya mengoptimalkan atribut dengan mengalikan terhadap bobot dari setiap kriteria.

$\left.\mathrm{Q} 1=0,5 \sum(0,6 * 10)+(1 * 5)+(0,7446 * 30)(1 * 10)+(1 * 30)+(0,85 * 15)\right)+\left(\prod\left(0,5^{10} * 1^{5} * 0,7446^{30} * 1^{10} * 1^{30} * 0,85^{15}\right)\right)$

$=0,5 \sum(5+5+22,338+10+30+12.75 \Pi(0,000976 * 1 * 0,000143 * 1 * 1 * 0,087354)$

$=42,544+6,0959$

$=48,6399$

$\left.\mathrm{Q} 2=0,5 \sum(1 * 10)+(0,9062 * 5)+(0,8510 * 30)(0,8888 * 10)+(1 * 30)+(0,9 * 15)\right)+\left(\prod\left(1^{10} * 0,9062^{5} * 0,8510^{30} * 0,8888^{10} * 1^{30}\right.\right.$ $\left.\left.* 0,9^{15}\right)\right)$

$=0,5 \sum\left(10+4,531+25,53+8,888+30+13,5 \prod(1 * 0,611111 * 0,007904 * 0,307638 * 1 * 0,205891)\right.$

$=46.2245+0,000152$

$=46,22456$

$\left.\mathrm{Q} 3=0,5 \sum(0,6 * 10)+(0,7395 * 5)+(0,6595 * 30)(0,9222 * 10)+(0,8888 * 30)+(0,85 * 1)\right)+\left(\prod\left(0,5^{10 *} 0,7395^{5} * 0,6595^{30}\right.\right.$ $\left.\left.* 0,9222^{10} * 0,8888^{30} * 0,85^{15}\right)\right)$

$=0,5 \sum\left(6+3,6975+19,785+9,222+26,664+12.75 \prod(0,000976 * 0,221152 * 0,0\right.$

$00003 * 0,444888 * 0,029115 * 0,087354)$

$=38,55925+3,663355$

$=42.222605$

$\left.\mathrm{Q} 4=0,5 \sum(0,6 * 10)+(0,6354 * 5)+(0,7765 * 30)(0,6777 * 10)+(0,7777 * 30)+\left(0,85^{*} 15\right)\right)+\left(\prod\left(0 \quad, 5^{10} * 0,6354^{5} * 0,7765^{30}\right.\right.$ $\left.\left.* 0,6777^{10} * 0,7777^{30} * 0,85^{15}\right)\right)$

$=0,5 \sum\left(6+3,177+23,295+6,777+23,331+12.75 \prod(0,000976 * 0,103570 * 0,000506 * 0,020435 * 0,000530 * 0,087354)\right.$

$=36,665+2,41955$

$=39,08455$

Q5 $\left.=0,5 \sum(0,6 * 10)+(0,6438 * 5)+(0,8510 * 30)+(0,8111 * 10)+(0,8888 * 30)+(0,85 * 15)\right)+\left(\prod\left(0,5^{10 *} 0,6438 \quad 5 \quad * \quad 0,8510^{30}\right.\right.$ $\left.\left.* 0,8111^{10} * 0,8888^{30 *} *, 85^{15}\right)\right)$

$=0,5 \sum\left(6+3,219+25,53+8,111+26,664+12.75 \prod(0,000976 * 0,110599 * 0,007904 * 0,123237 * 0,029115 * 0,087354)\right.$

$=40.637+1,337083$

$=41,974083$

$\left.\mathrm{Q} 6=0,5 \sum(1 * 10)+(0,6438 * 5)+(0,8510 * 30)(0,6777 * 10)+(0,8111 * 30)+\left(0,7^{*} 15\right)\right)+\left(\prod^{10 *} 0,6438^{5} * 0,8510^{30} * 0,6777^{10}\right.$ $* 0,8111^{\left.\left.30 * 0,7^{15}\right)\right)}$

$=0,5 \sum(10+3,219+25,53+6,777+24,333+10,5 \Pi(1 * 0,110599 * 0,007904 * 0,020435 * 0,001871 * 0,004747)$

$=40,1795+7,932996$

$=48,112496$

$\left.\mathrm{Q} 7=0,5 \sum(0,6 * 10)+(0,6438 * 5)+(0,7446 * 30)(0,6777 * 10)+(0,6666 * 30)+(0,73 * 15)\right)+\left(\prod\left(0,6^{10} * 0,6438^{5} * 0,7446^{30}\right.\right.$ $\left.\left.* 0,6777^{10} * 0,6666^{30 *} * 0,73^{15}\right)\right)$

$=0,5 \sum(6+3,219+22,338+6,777+16,665+10,95) \prod(0,006046 * 0,110599 * 0,000143 * 0,020435 * 2,190392 * 0,008909)$ $=32,9745+1,906561$

$=34,881061$

$\left.\mathrm{Q} 8=0,5 \sum(0,61 * 10)+(0,9375 * 5)+(1 * 30)\left(0,8111^{*} 10\right)+(0,7222 * 30)+(1 * 15)\right)+\left(\prod\left(0,61^{10} * \quad * \quad 0,9375^{5} * \quad 1^{30} * 0,8111^{10}\right.\right.$ $\left.* 0,7222^{30 * 115}\right)$ )

$=0,5 \sum(6,1+4,6875+30+8,111+21,666+15) \prod(0,007133 * 0,724196 * 1 * 0,123237 * 0,000057 * 1)$

$=171,129+1,81432$

$=172,943$

$\left.\mathrm{Q} 9=0,5 \sum(0,73 * 10)+(0,8854 * 5)+(0,9574 * 30)\left(0,8888^{*} 10\right)+(0,6666 * 30)+(0,87 * 15)\right)+\left(\prod\left(0,73^{10} * 0,8854^{5} * 0,9574^{30}\right.\right.$ $\left.\left.* 0,8888^{10} * 0,6666^{30} * 0,87^{15}\right)\right)$

$=0,5 \sum(7,3+4,427+28,722+8,888+16,665+0,87) \prod(0,042976 * 0,544123 * 0,270896 * 0,307638 * 2,190392 * 0,123819)$

$=33,436+2,642675$ 
Journal of Information System Research (JOSH)

Volume 2, No. 4, Juli 2021

ISSN 2686-228X (media online)

Hal: $260-267$

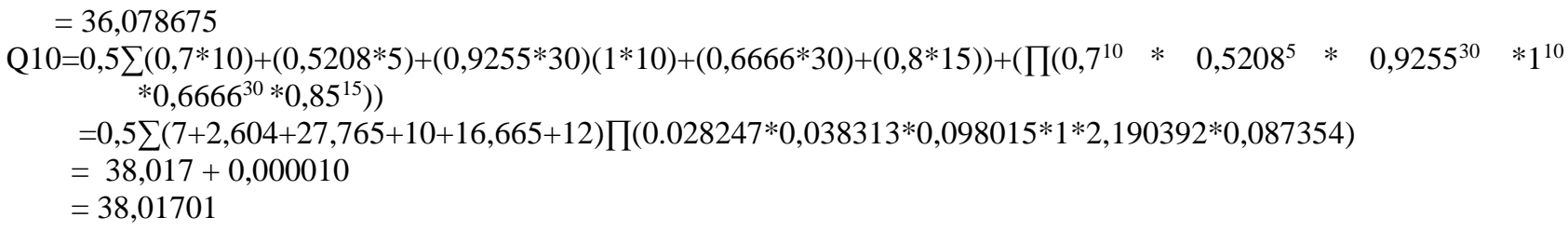

Kemudian menentukan nilai Altternatif tertinggi:

Tabel 2. Hasil dari setiap Alternatif

\begin{tabular}{cc}
\hline Alternatif & Hasil \\
\hline Budi Sianipar & 48,6399 \\
Dewi Farah & 46,22456 \\
Suminta & 42.222605 \\
Iwan & 39,08455 \\
Johanes & 41,974083 \\
Khadijah & 48,112496 \\
Resita & 34,881061 \\
Lia & 172,943 \\
Widodo & 36,078675 \\
Dicki & 38,01701 \\
\hline
\end{tabular}

Tabel 3. Perangkingan

\begin{tabular}{ccc}
\hline Alternatif & Hasil & Rangking \\
\hline Lia & 172,943 & 1 \\
Budi Sianipar & 48,6399 & 2 \\
Khadijah & 48,112496 & 3 \\
Dewi Farah & 46,22456 & 4 \\
Suminta & 42.222605 & 5 \\
Johannes & 41,974083 & 6 \\
Iwan & 39,08455 & 7 \\
Dicky & 38,01701 & 8 \\
Widodo & 36,078675 & 9 \\
Resita & 34,881061 & 10 \\
\hline
\end{tabular}

Hasil dari perhitungan menggunakan metode Waspas, bahwa alternatif bernama Lia merupakan alternatif terbaik sebagai penerima penempatan Hawker Brended Dunhill Filter

\subsection{Implementasi Program}

Form hasil keputusan berfungsi menampilkan hasil perangkingan dan hasil perangkingan yang tertinggi adalah yang akan mendapatkan penempatan Hawker Branded dunhill filter dari Pt. Bentoel Group Asmo Medan dan Hawker Branded dunhill filter tersebut akan di tempatkan di lokasi si penerima.

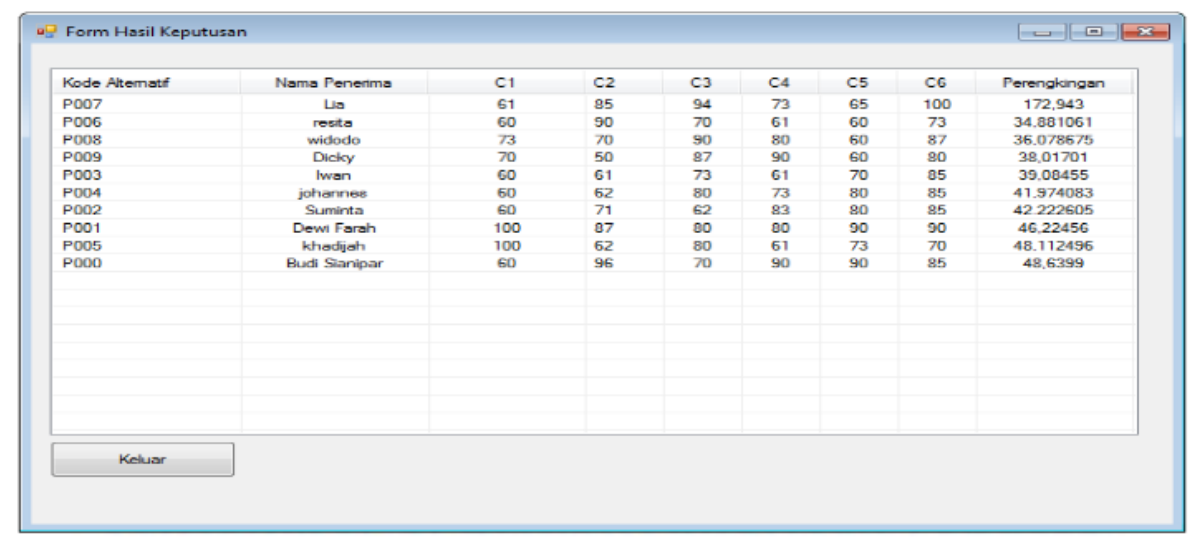

Gambar 1. Tampilan form hasil Keputusan

\section{KESIMPULAN}

Setelah melakukan penelitian didapatlah suatu proses cara Penempatan Hawker Branded Dunhill Filter yg strategis di PT. Bentoel Group Asmo Medan. yaitu dengan cara menyeleksi beberapa kandidat yang memenuhi kriteria guna memilih 
lokasi penempatan penempatan Hawker Branded Dunhill Filter. Metode Weighted Aggregated Sum Product Assesment (WASPAS) dapat diterapkan dalam menentukan penempatan Hawker Branded Dunhill Filter dengan cara menentukan kriteria penempatan, pengambilan keputusan dengan menambahkan alternatif dan nilai bobot pada setiap kriteria, hasil yang paling tinggi dari setiap alternatife yang akan menerima penempatan lokasi Hawker Branded Dunhill Filter. Aplikasi sistem pendukung keputusan yang dirancang dengan menggunakan Microsoft visual basic 2008, dapat menentukan penempatan lokasi Hawker Branded Dunhill Filter yang didalamnya terdapat form login, form menu utama, form input menu alternatif, form Input Menu Kriteria, Form Input Bobot Kriteria Pada Setiap Alternatif, tampilan form hasil Keputusan

\section{REFERENCES}

[1] S. Kusumadewi, S. Hartati, A. Harjoko, and Retantyo Wardoyo, Fuzzy Multi-Attribute Decision Making (FUZZY MADM). 2006.

[2] Mesran, K. Tampubolon, R. D. Sianturi, F. T. Waruwu, and A. P. U. Siahaan, "Determination of Education Scholarship Recipients Using Preference Selection Index,” Int. J. Sci. Res. Sci. Technol., vol. 3, no. 6, pp. 230-234, 2017.

[3] D. Assrani, N. Huda, R. Sidabutar, I. Saputra, and O. K. Sulaiman, "Penentuan Penerima Bantuan Siswa Miskin Menerapkan Metode Multi Objective Optimization on The Basis of Ratio Analysis (MOORA)," Penentuan Penerima Bantu. Siswa Miskin Menerapkan Metod. Multi Object. Optim. Basis Ratio Anal., vol. 5, no. 2407-389X (Media Cetak), pp. 1-5, 2018.

[4] A. T. Hidayat, N. K. Daulay, and Mesran, "Penerapan Metode Multi-Objective Optimization on The Basis of Ratio Analysis (MOORA) dalam Pemilihan Wiraniaga Terbaik," J. Comput. Syst. Informatics, vol. 1, no. 4, pp. 367-372, 2020.

[5] S. Barus, V. M. Sitorus, D. Napitupulu, M. Mesran, and S. Supiyandi, "Sistem Pendukung Keputusan Pengangkatan Guru Tetap Menerapkan Metode Weight Aggregated Sum Product Assesment ( WASPAS )," MEDIA Inform. BUDIDARMA, vol. 2, no. 2, pp. 10-15, 2018.

[6] T. Limbong et al., Sistem Pendukung Keputusan: Metode \& Implementasi. Medan: Yayasan Kita Menulis, 2020.

[7] D. Nofriansyah and S. Defit, Multi Criteria Decision Making (MCDM) pada Sistem Pendukung Keputusan. 2018.

[8] N. K. Daulay, B. Intan, and M. Irvai, "Comparison of the WASPAS and MOORA Methods in Providing Single Tuition Scholarships,” IJICS (International J. Informatics Comput. Sci., vol. 5, no. 1, pp. 84-94, 2021.

[9] N. K. Daulay, "Penerapan Metode Waspas Untuk Efektifitas Pengambilan Keputusan Pemutusan Hubungan Kerja,” J. Sist. Komput. dan Inform., vol. 2, no. 2, pp. 196-201, 2021. 